\title{
Quality Changes of Burger from Vegetable, Wheat Flour, Rice Flour with Fat Emulsion during Frozen Storage
}

\author{
GANEESHA DE SILVA ${ }^{1}$, UPUL MARAPANA ${ }^{1,3^{*}}$, ANTON KALUBOWILA ${ }^{2}$ NIROSH LALANTHA ${ }^{2}$ and THAKSALA \\ SERESINHE $^{1}$
}

\author{
${ }^{1}$ Department of Animal Science, Faculty of Agriculture, University of Ruhuna, Mapalana, Kamburupitiya, \\ Sri Lanka \\ ${ }^{2}$ Keells Food Products PLC, Ja-ela, Sri Lanka
}

\begin{abstract}
Changes in physico-chemicals, microbial and sensory quality of newly formulated veggie burgers prepared from rice flour, wheat flour with (RW5E) and without (RIOE) fat emulsion, rice flour isolated soya protein (ISP) with (RI5E) and without (RIOE) fat emulsion were periodically analyzed during frozen storage at $-18^{\circ} \mathrm{C}$ for 90 days. Sensorial attributes were altered with fat emulsion and rice flour wheat flour addition $(p<0.05)$. RW5E was found to be the best sample based on sensory method. Further proximate analysis revealed that RW5E had gained 51.68\% moisture, $8.38 \%$ fat, 48.33\% TS, 36.84\% ONF and 3.1\% ash after 90 days of storage and RW5E was the best option to lessen purge and increase WHC followed by others. The results of microbial, $\mathrm{pH}$ and peroxide value indicated that all four products were well within the recommended standards. This study indicated that the addition of RW5E to veggie burger exhibited reasonable shelf-life and acceptable in terms of nutritional value and sensory attributes.
\end{abstract}

Keywords: Veggie burger, Chickpea, Rice flour, Wheat flour, ISP

\section{Introduction}

In today's world, there has been market trend derived towards convenient foods because consumers lead increasingly busy lives (Lawrie, 1979). Among ready to serve foods, Hamburgers are acceptable (Egbert et al., 1991). Menkhaus et al., (1993) indicated that consumer concerns regarding beef products were related to cholesterol and high price. Reginaldo et al., (2007) have mentioned typical composition of beef burgers is about $20 \%$ fats. Each of these factors exhibited a significant negative effect on the quality perception of beef burger. If we replace meat in burger from vegetable there's no needed to use $\mathrm{NO}_{3}^{-}$or $\mathrm{NO}_{2}^{-}$. However $\mathrm{NO}_{3}^{-} \& \mathrm{NO}_{2}^{-}$have been reported to lead to the formation of nitrosamines, which are carcinogenic in nature. So, this research was intended to develop a veggie burger using vegetable based ingredients without preservative and investigate whether it can be used as a beef meat analogue as convenience-oriented product. In addition, the effect of binder and fat emulsion on the veggie burger qualities stored at $-18^{\circ} \mathrm{C}$ for 90 days was tested.

\section{Materials and Methods}

Preparation of veggie burgers: These studies were carried out on hit and trial basis. Initially, trial was carried out to find out the suitable vegetable mixture [Spinach (5.5\%), Bean $(6.0$ $\%$ ), Capsicum (5.5\%), Carrot (6.0\%) and Mushroom (11.2\%)]

\footnotetext{
*Correspondence author, E-mail: umarapana@yahoo.com

${ }^{3}$ Present address: Dept. of Food Science and Technology, Faculty of Applied Sciences, University of Sri Jayawardenepura, Gangodawila, Nugegoda, Sri Lanka.
}

proportion based on sensory properties. Then preliminary trials were conducted to select suitable vegetable form (blanched or non-blanched) based on the color persistence during chill storage. Further, trialed was conducted to select better legume type as a burger base out of Chickpea, Chickpea dhal, Mung bean and Lentil. Then Chickpea was selected based on maximum subjective qualities as a burger base. In addition four binder mixtures $(1: 1)$ were tested namely Rice flour: wheat flour (RW), rice flour: ISP (RI), wheat flour: ISP (WI), Chickpea flour: ISP(CI). Finally, RW and RI were selected based on significantly higher mean scores.

Experimental design for veggie burger production: The main mixture, composed of vegetable mix (34.2\%), Spice mix (10.6 $\%)$ and chickpea $(25.2 \%)$ was processed in a chopper. The burger dough was sub-divided into four equal portions; to the first portion RW $(25 \% \mathrm{w} / \mathrm{w}) 5 \mathrm{E}(5 \% \mathrm{w} / \mathrm{w})$ and to the second portion only RW $(30 \% \mathrm{w} / \mathrm{w})$ was added. To the other portions RI $(25 \% \mathrm{w} / \mathrm{w}) 5 \mathrm{E}(5 \% \mathrm{w} / \mathrm{w})$ and RI $(30 \% \mathrm{w} / \mathrm{w})$ were added respectively. Dough was thoroughly mixed by rechopping in the bowl chopper. $42 \mathrm{~g}$ of this each mixture placed and pressed by using manual ellipse shaped mould then deep fried at $180^{\circ} \mathrm{C}$ for 1 min until the core temperature was around $75^{\circ} \mathrm{C}$. Then product was sealed in portion of four pieces and transferred to air blast freezer at $-18^{\circ} \mathrm{C}$.

Sensory evaluation: Fifteen panelists were involved to assess the sensory properties according to a 6-point hedonic rating scale. Veggie burger sample belonging different groups were examined after 1 and 90 days of storage for color, vegetable pieces presence, texture, aroma, juiciness, oiliness, spiciness, 
saltiness and overall acceptability. According to the score table, scores (4-5) indicated "high quality", scores (2-3) indicated "moderate quality" and sores (0-1) indicated the limit of "unacceptability".

Microbiological analysis: The burger samples were analyzed for their microbial contamination as Salmonella, Staphylococcus aureus, E. coli, TPC, Yeast and Mould during three months of period in every two weeks of interval. $10 \mathrm{~g}$ of sample from each package was homogenized into a sterile stomacher bag with $90 \mathrm{ml}$ of $2 \% \mathrm{w} / \mathrm{w}$ peptone water for 30 seconds. Serial dilutions were prepared using the same diluents. Duplicate 0.1 or $1 \mathrm{ml}$ inoculums of appropriate dilutions were spread on the followings, TPC on petirifilm ${ }^{\mathrm{TM}}$ aerobic count plate, $E$ coli on petirifilm ${ }^{\mathrm{TM}}$. E coli count plate incubated at $35^{\circ} \mathrm{C}, \mathrm{S}$. aureus on Baird parker medium, spread plates incubated at $37^{\circ} \mathrm{C}$ (Harrigan and McCance, 1976), Yeast and mould on PDA media and pour plates were incubated at $25^{\circ} \mathrm{C}$. Salmonella were determined using Salmonella screening device and sodium Biselenite broth (Gray and Patrick, 1995)

Determination of $\mathbf{p H}$ : Sample was homogenized with distilled and de-ionized water in ratio 1:1 (w/v) in stomacher. Then $\mathrm{pH}$ was measured on $20 \mathrm{~g}$ sample in $80 \mathrm{ml}$ de-ionized water by using a digital pH meter (Model: METTLER TOLEDO 320S).

Determination of peroxide value: Peroxide values were determined Iodometric titration according to the method described by IUPAC for analysis of oils, fats and derivatives (1989) and calculated as meq per $1 \mathrm{~kg}$ of fat or oil.

Proximate analysis: Proximate composition as total solid, fat, organic non fat, moisture, ash was analyzed during the storage period according to the method described in AOAC, (1984).

Determination of cooking loss: Cooking loss was determined according to Visessanguan et al., (2004). The weights of the veggie burgers were measured before cooking and after cooking. Then the loss of weight after cooking would be calculated.

Determination of purge loss: Three sample numbers from each sample were weighed.Then they were vacuum packed and placed in a single layer at $-18^{\circ} \mathrm{C}$. Purge loss was determined by reweighing blotted samples following 2 weeks of storage. Same procedure was done for each sample (AOAC, 1984).

Determination of water holding capacity: Water holding capacity was calculated according to the given formula.

$$
\mathrm{WHC}=\frac{B-C}{A} \cdot 100
$$

Where,
A- Initial weight of the sample
B - Weight of the sample after centrifuging
C - Weight of the sample after oven drying

Statistical analysis: Sensory analysis data were analyzed by using non parametric Kruskal Wallis one way ANOVA in SPSS 10.0. Objective data were analyzed by analysis of variance (ANOVA) in binder $\times$ emulsion $\times$ storage factorial design. Moreover, means were separated using one way ANOVA for treatment at the same storage and storage time for individual treatment. When ANOVA showed significant treatment effect $(\mathrm{p}<0.05)$, mean separation was done by using the DMRT.

\section{Results and Discussion}

Sensorial characteristics were altered with emulsion addition especially in texture and juiciness. Therefore, the sample coded as RW5E was selected as the best one on the basis of sensory score rating remained between good and very good during storage $(\mathrm{p}<0.05)$. There were no significant differences $(p>0.05)$ between color, presence of vegetable pieces and spiciness in samples throughout storage but there were significant difference $(p<0.05)$ between samples except presence of vegetable pieces and spiciness. For all samples blanched vegetable were used. Therefore, it may be the reason for degradation in color with the storage time. However, the samples gained the different mean scores for color would be due to the emulsion and ISP used in samples.

E coli, Staphylococcus aureus, PDAC and salmonella were totally absent by 90 days under the frozen $\left(-18^{\circ} \mathrm{C}\right)$ storage. So, the hygienic condition of the sample would be in satisfactory level. SLS (1981) recommended that more than $10^{2} \mathrm{CFU} / \mathrm{g}$ of mould count will be unsatisfactory for fried products.

The microbial load of veggie burger was declined during storage because of the antimicrobial effects of the ingredients (i.e. spices), vegetable base used in the burger formulation, subjected to high temperature during the cooking process, prior blanching of vegetables cause destruction of microorganisms and freezing also inhibit of their growth. The approximate quantitative range of TPC is $10^{3}-10^{7} \mathrm{CFU} / \mathrm{g}$ for the acceptability of fresh and frozen vegetable. There is no standard for veggie burger in Sri Lanka but according to hamburger standard maximum TPC was given as $10^{7} \mathrm{CFU} / \mathrm{g}$ (Wehr, 1982). SLS (1991) has recommended that the maximum level of TPC for precooked meat products would be $10^{6} \mathrm{CFU} /$ g. Considering these value, TPC were satisfactory in all samples up to 90 days of storage (Figure 1).

At the beginning i.e. day 0 , the $\mathrm{pH}$ values for RW5E, RW0E, RI5E and RI0E were measured as 6.87, 6.90, 6.90 and 6.97 respectively and these values dropped orderly to the values of $6.67,6.70,6.70 \& 6.73$ at days 90. Forrest et al., (1975) determined that the reduction of $\mathrm{pH}$ during the storage could be due to the microbial activity and oxidation of fat and oils.

The statistical results showed that there were significant differences $(p<0.05)$ between the samples and with the storage time for peroxide values. They were relatively high even on the first day. That might be due to the oil used for frying the product was highly unsaturated and more susceptible for 


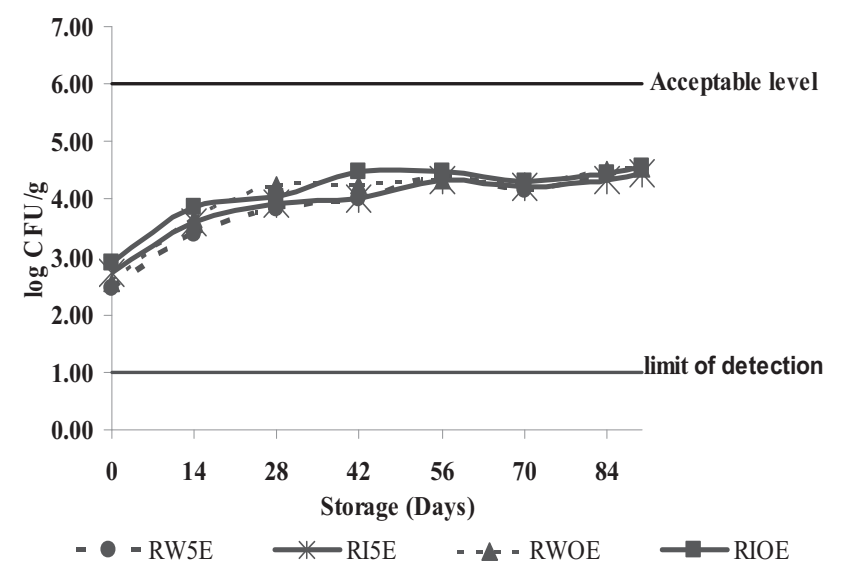

Figure 1. Variation of TPC with storage time

lipid oxidation. Coultate et al., (1989) found that peroxide value of fresh oils could be less than $10 \mathrm{meq} / \mathrm{kg}$, when it rose between 30 to $40 \mathrm{meq} / \mathrm{kg}$, a rancid taste could be noticeable. The result suggested that the peroxide values in all samples were in the range of good quality limit up to 90 days of storage at $-18^{\circ} \mathrm{C}$ (Table 1$)$.

Table 1. Variation of Peroxide values of veggie burger with storage time

\begin{tabular}{cllll}
\hline \multirow{2}{*}{ rroup } & \multicolumn{4}{c}{ Storage (Days) } \\
\cline { 2 - 5 } & $\mathbf{0}$ & $\mathbf{3 0}$ & $\mathbf{6 0}$ & $\mathbf{9 0}$ \\
\hline RW5E & $7.84^{\mathrm{a}^{* / w^{* *}}}$ & $7.96^{\mathrm{b} / \mathrm{x}}$ & $8.88^{\mathrm{c} / \mathrm{x}}$ & $9.62^{\mathrm{d} / \mathrm{x}}$ \\
RI5E & $7.84^{\mathrm{a} / \mathrm{w}}$ & $8.88^{\mathrm{b} / \mathrm{w}}$ & $9.72^{\mathrm{c} / \mathrm{w}}$ & $9.88^{\mathrm{d} / \mathrm{wx}}$ \\
RWOE & $7.57^{\mathrm{a} / \mathrm{x}}$ & $7.61^{\mathrm{a} / \mathrm{z}}$ & $8.52^{\mathrm{b} / \mathrm{z}}$ & $9.61^{\mathrm{c} / \mathrm{x}}$ \\
RIOE & $7.55^{\mathrm{a} / \mathrm{x}}$ & $7.83^{\mathrm{a} / \mathrm{y}}$ & $8.63^{\mathrm{b} / \mathrm{y}}$ & $10.22^{\mathrm{c} / \mathrm{w}}$ \\
\hline
\end{tabular}

${ }^{k}$ Means in the same row and $* *$ Means in same column given with different letters are significantly different from the other $(\mathrm{p}<0.05)$

Other physico-chemical parameters such as total solid, moisture, fat and ONF were significantly changed $(\mathrm{p}<0.05)$ in rice flour ISP without emulsion type than other three samples. The reduction of moisture and fat content lead to reduce the succulent characteristic of final product. With the storage time, the ash content did not change significantly $(\mathrm{p}>0.05)$.

Table 2. Changes in WHC of veggie burger samples during storage

\begin{tabular}{cllll}
\hline \multicolumn{5}{c}{ burger samples during storage } \\
\hline Sroup & \multicolumn{4}{c}{ Storage (Days) } \\
& 0 & 30 & 60 & 90 \\
\hline RW5E & $46.81^{\mathrm{a}^{* / y^{* *}}}$ & $46.76^{\mathrm{a} / \mathrm{w}}$ & $46.50^{\mathrm{b} / \mathrm{w}}$ & $45.98^{\mathrm{c} / \mathrm{w}}$ \\
RI5E & $47.00^{\mathrm{a} / \mathrm{w}}$ & $46.67^{\mathrm{b} / \mathrm{w}}$ & $46.18^{\mathrm{c} / \mathrm{x}}$ & $45.33^{\mathrm{d} / \mathrm{y}}$ \\
RWOE & $46.71^{\mathrm{a} / \mathrm{z}}$ & $46.49^{\mathrm{b} / \mathrm{x}}$ & $46.01^{\mathrm{c} / \mathrm{y}}$ & $45.44^{\mathrm{d} / \mathrm{x}}$ \\
RIOE & $46.97^{\mathrm{a} / \mathrm{x}}$ & $46.27^{\mathrm{b} / \mathrm{y}}$ & $45.82^{\mathrm{c} / \mathrm{z}}$ & $44.81^{\mathrm{d} / \mathrm{z}}$
\end{tabular}

* Means in the same rows and ** Means in the same columns given with different superscripts letters are significantly different from the other $(\mathrm{p}<0.05)$
The WHC was significantly reduced $(\mathrm{p}<0.05)$ within samples during the storage period (Table 2). This may be due to the change in macro- molecules during frozen storage, which reduces the WHC and it leads to reduction of juiciness. The reduction of WHC, the quality of the final product can suffer, because of the loss of more than the usual amount of water as described by Man (2002) which resulting off-flavor formed as "stale" or "warmed up" from fat oxidation.

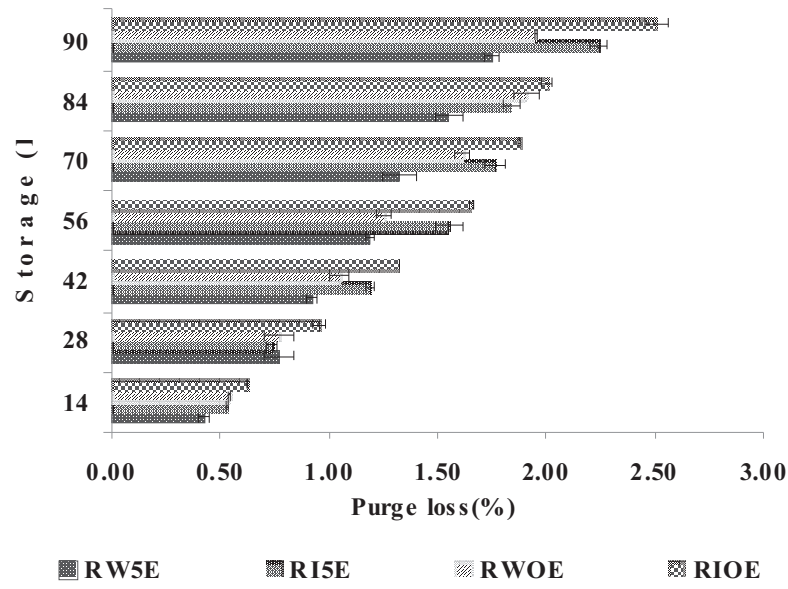

Figure 2. Purge loss in veggie burger samples during storage

Purge loss was significantly differ $(\mathrm{p}<0.05)$ between samples and with the storage time (Figure 2). The decline in WHC reflected an increase in the ability of fluid to flow (Purge). However, the purge loss depends on the rate of crystallization formed during freezing (Drummond and Sun, 2005). After the product has been frozen, the sublimation process will occurs during thawing from the product surface. If it is excessive during thawing a dry and spongy product may occurred. This may be the reason of ISP rice flour with out emulsion had dry nature.

There were no any significant differences among four samples for cooking loss with respect to the binder or emulsion used ( $p>0.05)$. Almost the same moisture content in products and amount of vegetable used in all samples could be the reason for that.

\section{Conclusion}

There was a significant increment among sensory scores of veggie burger in respect to addition of emulsion $(p<0.05)$. According to sensory results, the sample which contained RW5E was selected as the best with respect to the color, texture, aroma, juiciness, oiliness, saltiness and overall acceptability $(\mathrm{p}<0.05)$ followed by other samples during the storage period. RW addition was found to have a significant effect in improving the reduction of purge and WHC because of RW can have ability to avoid the dryness in products. Among the binders used, RW was found to be the best one, which can maintain the overall quality of product. Storage 
time under frozen conditions caused the variation in qualities except ash. The development of a veggie burger by using RW has shown to be an approach for processed meat analogue thereby improving the nutritional value, shelf-life and sensory qualities. However, further studies are still needed to improve the juiciness of the sample which contains rice flour, wheat flour with fat emulsion.

\section{References}

AOAC (1984). Official Methods of Analysis (14 ${ }^{\text {th }}$ Ed), Association of Official Analytical Chemists, Washington, D.C., USA.

Coultate T. P. (1989). Food: the chemistry of its components $\left(2^{\text {nd }} \mathrm{Ed}\right)$, The Royal society of chemistry, Cambridge.

Drummond L. S. and Sun D. W. (2005). Feasibility of water immersion cooking of beef joints: Effect on product quality and yield. J. Food engineering, 77: 289-294.

Egbert W. R., Huffman D. L., Chen C. M. and Dylewski D. P. (1991). Development of low-fat ground beef. Food Tech., 45: 68-73.

Forrest J. C., Alberle E. D., Hedrick H. B., Judge M. D. and Merkel R. A. (1975). Principles of meat science, Freeman and company publications, Chapman hall, New York.

Gray L. D. and Patrick R. (1995). Escherichia, Salmonella, Shigella and Yersina in manual of clinical microbiology $\left(6^{\text {th }} \mathrm{Ed}\right)$, American society for microbiology, Washington, D.C., American society for microbiology, 450- 456.
Harrigan W. F. and McCance M. E. (1976). Laboratory Methods in Food and Dairy Microbiology, Academic Press Inc., London.

IUPAC (1989). Standard methods for analysis of oils, fats and derivatives, Vol.54, No.6, pp. 1257-1295.

Lawrie R. A. (1979). Meat Science, Pergamon press, New York.

Man D. (2002). Shelf-Life. Food Industry Briefing Series. Blackwell Science. Oxford. U.K.

Menkhaus D. J., Colin D. P. M., Whipple G. D. and Field R. A. (1993). The effects of perceived product attributes on the perception of beef. Agribusiness, 9: 57-63.

Reginaldo A. T., Jorge M. F., Ingrid T. S., Thaise C. F. N., Vladimir D. R. and Anna L.C.H. (2007). Changes on lipid profile in beef burgers prepared with rosemary extract and submitted to E-beam processing. Radiation Physics and Chem., 63-69.

Sri Lanka Institute of Standards (1991). 161: 1991, Colombo, Sri Lanka.

Visessanguan W., Benjakul S., Riebroy S. and Thepkasikul P. (2004). Changes in composition and functional properties of proteins and their contributions to Nham characteristics. Meat Sci., 66(2): 579-588.

Wehr H. M. (1982). Attitudes and Policies of Govermental Agencies on Microbial Criteria for Foods, an Update. Food Tech., 36: 45-54. 